\title{
CONSIDERATIONS FOR COMMERCIAL PLANT INTRODUCTION FROM PUBLIC GARDENS
}

\author{
Matthew D. Taylor ${ }^{1}$
}

\begin{abstract}
Public gardens can benefit from the introduction of new plants to the horticulture industry. There are many ways to develop and discover new plants in the public garden setting, whether it be through plant breeding, exploration or simply discovering a sport or mutation. The characteristics of plants suitable for the commercial display industry include short time to flower, no day-length requirement, easy and fast propagation, natural branching and inherent short height. Over the last 20 years, the process of plant development and introduction has changed enormously. Now, elements such as strong brands and marketing campaigns, plant patents or plant breeders' rights, trademarks and the ability of a new plant to thrive in mass production settings are important considerations when making a new plant release. In addition, public gardens must evaluate potential commercial partners to ensure that they get the maximum benefits from the process. This paper describes that process and gives recommendations for some of the key stages with reference to plants released by Longwood Gardens in Philadelphia.
\end{abstract}

\section{INTRODUCTION}

Throughout history, public gardens and arboreta have been the source of new ornamental plant material to the horticulture industry. The majority of these plants were obtained through domestic or international plant exploration, through plant breeding programmes or were selected from seed lots. In 1956, Dr Russell Seibert, the first Director of Longwood Gardens, recognised the need for a broader selection of ornamental plants in the United States (Aniśko, 2006). He addressed this by implementing Longwood's Plant Exploration Programme with the goal of adding to the palette of plants available to gardeners and amplifying the displays in Longwood Gardens' conservatory and outdoor gardens. Since 1956, Longwood has been involved in 70 plant exploration trips across the globe to every continent except Antarctica. Partners for the trips have included other gardens, arboreta, government entities, private nurseries and many foreign institutions.

Over the course of these expeditions, more than 14,000 plant specimens have been collected. From these, however, Longwood and partners have only introduced a minute percentage (less than 1 per cent) to the industry. Furthermore, many of these plants are now difficult to find in the trade or cannot be located at all. However, some introductions fare well. For example, the first cultivars of the ever popular New Guinea impatiens were

1. Matthew D. Taylor is Research Manager at Longwood Gardens.

Address: Longwood Gardens, PO Box 501, Kennett Square, PA 19348, USA.

Email: mtaylor@longwoodgardens.org 
bred from plants of Impatiens hawkeri collected in New Guinea in 1970 by Longwood Gardens and the US Department of Agriculture (Fig. 1). These early cultivars are not currently available. However, these selections paved the way for new cultivars that are continually added to the market. Another popular example is Ilex crenata 'Sky Pencil', which was collected in 1985 during a trip to Japan by Longwood Gardens and the US National Arboretum (Fig. 2). The National Arboretum released this cultivar in 1992, and it continues to be widely available in the horticulture industry and a popular garden plant. However, the success of these examples is rare among the tens of thousands of plants collected by public gardens.

The under-utilisation of plants from exploration trips has been recognised in the past. Lighty (1999) states that the success of plant exploration programmes should not be measured in the number of plants returned alive but in the plants that come out of the programmes that have a positive impact on American horticulture. The evolution and success of plant exploration programmes is a topic for another discussion. But when we evaluate past plant releases from these programmes, what could have been done differently to make them more successful? What strategies should be implemented by public gardens and arboreta to ensure all plants they release are successful?

New plants for the horticulture market face many challenges compared to decades past. Major marketing campaigns, strong brands, plant patents or plant breeders' rights, trademarks and the ability of a new plant to thrive in mass production settings

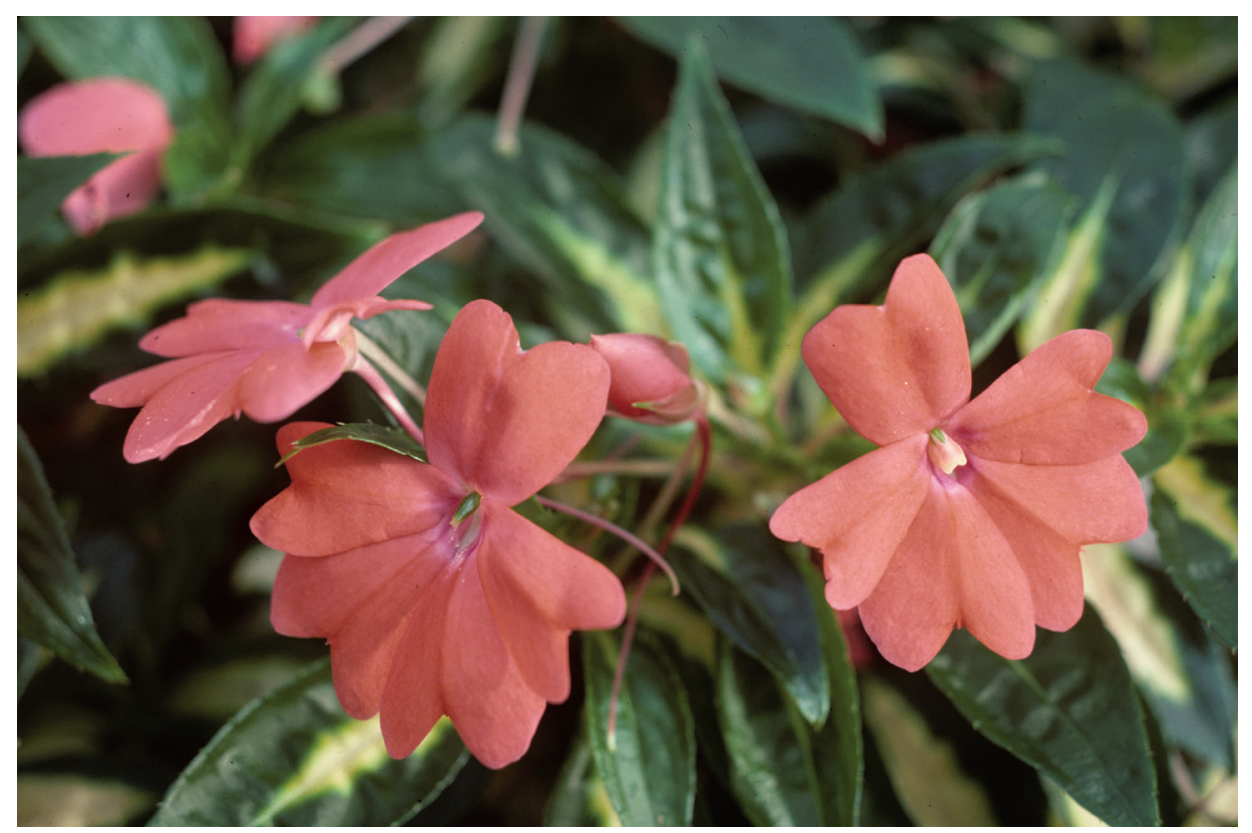

Fig. 1 Impatiens 'Trapeze': one of the first New Guinea impatiens cultivars to be released, bred at Longwood Gardens from plants collected in New Guinea in 1970 with the US Department of Agriculture. Photo: Dr Robert Armstrong. 




Fig. 2 A hedge created from Ilex crenata 'Sky Pencil', originally collected in 1985 on a plant exploration trip to Japan by Longwood Gardens and the US National Arboretum. Photo: Larry Albee.

are significant considerations with a new plant release. Even more importantly, is it a good garden plant for the consumer? What sets it apart from the plethora of material competing in today's ornamental plant market? Even with all the new plants coming out today, there are still tremendous opportunities for new ornamental plants in the market. Sales of ornamental plants in the USA alone have increased by 11 per cent to 24 per cent since 2009 (Table 1). The objective of this article is to present considerations for public gardens when contemplating the introduction of a new plant, particularly a commercial introduction.

\begin{tabular}{|l|c|c|}
\hline \multicolumn{1}{|c|}{ Commodity } & 2014 sales & Increase in sales 2009-2014 \\
\hline Nursery stock & \$4.27 billion & $11 \%$ \\
\hline Annual bedding plants & \$2.57 billion & $11 \%$ \\
\hline Potted flowering plants & $\$ 1.08$ billion & $24 \%$ \\
\hline Herbaceous perennials & \$945 million & $12 \%$ \\
\hline
\end{tabular}

Source: USDA, 2014

Table 1 Sales of top commodities in US ornamental horticulture in 2014 and percentage increase from 2009 to 2014 . 


\section{BENEFITS OF PLANT INTRODUCTION}

There are many benefits to the release of a named cultivar to the horticulture industry. These benefits vary depending on the type of plant released and the potential market. Benefits to public gardens of introducing plants are the potential they offer.

\section{Revenue for the organisation as whole}

Ideally, a new plant will be protected by a patent, trademark or plant breeders' rights; it will have an associated royalty and will be a source of promotion and revenue for a garden. Very few public gardens regularly introduce protected plant material into the market. Plant breeding companies work at a rapid pace to create and release new annual, perennial and woody plants to the market. Public gardens typically do not have the resources to compete with this rate of release, nor is it a part of the mission of most public gardens. However, there is always the possibility that a plant discovered or developed at a public garden could fit into the mainstream model. Characteristics of these types of plants will be discussed below.

\section{Promotion of the name and reputation of the organisation}

Regardless of whether or not the plant is protected and generates royalties, another meaningful benefit of plant introduction is the promotional value. The selected cultivar name is an opportunity to recognise the institution. If the plant is to be considered for the mass market, partnership with a plant marketing company is required. This partner will want to be involved in selecting the name, as the name chosen can considerably impact success in the market. At Longwood Gardens, the policy governing plant introductions states that the cultivar name must be mutually agreed between Longwood Gardens and the plant marketing or distribution company. The selected name must also include 'Longwood' or the name of the Longwood founder (Pierre du Pont) or that of his wife (Alice du Pont) in order to extend the Longwood Gardens brand (Fig. 3). Another branding opportunity when selecting a cultivar name is to highlight a special area of the garden. For example, Longwood's most recent release, Clivia minata 'Longwood Chimes', refers to the Chimes Tower, built by Pierre du Pont in 1929 (Fig. 4). Finally, when selecting a cultivar name, it is important to follow the rules of the International Code of Nomenclature for Cultivated Plants (Brickell et al., 2009).

\section{Supporting other programmes and activity in the organisation}

New plant introductions can feed into and support some of the day-to-day promotional and public activities of the garden such as supporting membership benefits and encouragements, providing display opportunities in the plant sales area (and thereby a 


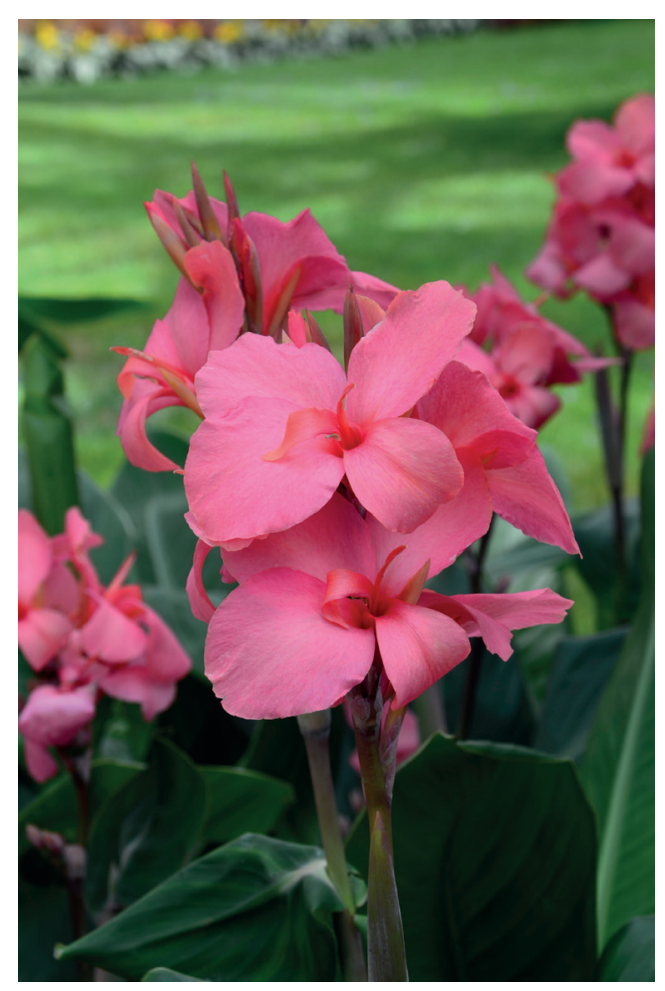

Fig. 3 Canna 'Mrs. Pierre S. du Pont'. Photo: Candie Ward.

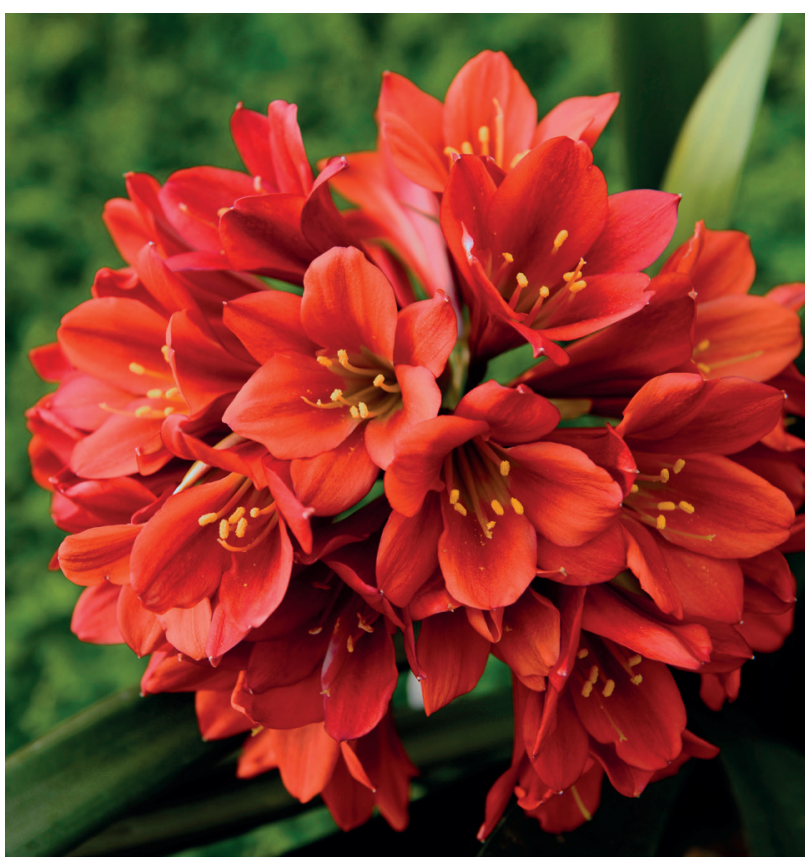

Fig. 4 Longwood's most recent release, Clivia minata 'Longwood Chimes', refers to the Chimes Tower, built by Pierre du Pont in 1929. Photo: Alan Petravich. 
further opportunity for revenue generation) and contributing to public programmes in the form of focused activities or event opportunities. Members can be given exclusive access for early purchase before a new introduction is available to the public; the plant can be the feature of plant sales or can be a highlight for programming. Native plants, pollinators, plants for a specific geographic region or beauty in the landscape are often the focus of programming at public gardens. The distribution of plants during these programmes greatly resonates with guests and members. Furthermore, using a plant that was developed or selected at that particular public garden is a very effective tool to drive attendance and expand the impact of such programming. A programming theme can also highlight distinct attributes of the new plant such as water conservation or native provenance to tie in with other public programmes.

\section{BREEDING AND SELECTION}

Only a handful of public gardens and arboreta in the USA have active breeding programmes. One of the most successful programmes is Chicagoland Grows ${ }^{\circledR}$. This was established in 1986 and is a unique partnership between Chicago Botanic Garden, the Morton Arboretum in Illinois and the Ornamental Growers Association of Northern Illinois. The goal of the introduction programme is to provide and promote plants that are well adapted to the Midwestern USA or similar landscapes. Under it the scope of plant characteristics and cultural requirements are defined and each selection must fit within it; this provides a framework for breeding and selection objectives. There are two formal plant breeding programmes at the Morton and Chicago Botanic Garden that generate new cultivars for introduction and a network of growers providing feedback on both garden performance and performance in a production setting. Additionally, Chicagoland Grows ${ }^{\circledR}$ is an established, recognisable brand and has a network for marketing and plant distribution. This is an exemplary scenario for plant development and introduction from public gardens.

Although most gardens do not have formal breeding or exploration programmes, there are still opportunities to select new plants for release. At most gardens, plant trials are taking place. These can range from formal, scientifically designed trials with data collection to simple, anecdotal evaluation of plant performance. In either case, there is the chance of discovering a plant that is unique or better than what is currently available on the market. These selections could come from variable plant populations that originate from purchased or collected seed lots. At most gardens, there are copious seed lots to be harvested at certain times of the year across the collection. Furthermore, these lots can be easily created by selecting target species, planting them near to one another and letting Mother Nature make some crosses. Many cultivars in the market today are the result of someone with a good eye for plants being in the right place at the right time. When discovered, random mutations or sports on established cultivars can also be a source of new and unique plants. 


\section{CHARACTERISTICS OF MARKETABLE PLANTS}

Imagine a new and interesting plant is discovered at your garden, the selection is shared with a plant introduction company, the plant is introduced and now royalty payments arrive regularly. If only it were that simple! Often, the characteristics of plants that professional horticulturists and avid gardeners find interesting and unique are very different from those which are desired by the horticulture industry. Short time to flower, no day-length requirement, easy and fast vegetative/tissue culture propagation, natural branching and inherent short height are some of the ideal characteristics of highly successful commercial introductions (Schoellhorn, 2009). The primary production season in the USA is from February to May and spring plant sales heavily exceed summer and autumn sales. For this reason, long-day crops are often dropped in favour of earlier flowering plants (Schoellhorn, 2009). Furthermore, crops that require only slight modifications to standard production protocols face a higher barrier than those that fit into traditional models for herbaceous annual production.

Even if a plant does not possess each of the above characteristics, it may still have a place in the market. There is a push for breeders to start thinking more about the end consumer and developing plants that have multiple positive attributes such as attracting pollinators, extended season performance and drought tolerance (Wright, 2016). Breeding and selection for more consumer-based attributes ultimately leads to better plants that are more aligned with market demand. Surveys have also shown that consumers are willing to pay a premium for plants grown at facilities that practice water conservation (D'Alessio et al., 2015).

The most important characteristic of a new plant is that it is different from what already exists. There are several ways to determine the extent of competition a plant may be up against when introduced. Plant catalogues and the internet can be used to investigate this. The US Patent and Trademark Office website (United States Patents and Trademark Office, 1994) can also provide information on plants that have already been patented.

\section{TR I A LLING}

Two other important characteristics of successful plants are great garden performance and ease of production. The best way to determine the first of these is through plant trials. Most breeding companies will test plants under scientifically designed trials for several years across a broad geographic range. Some have trial sites across a region of the country, across the entire country and even around the globe. The extent of these trials helps companies to determine the most appropriate markets for the plant and when sales in these markets should begin. They are also able to evaluate the second characteristic - ease of production - by assessing details such as propagation efficiency, greenhouse culture and how the plant fits into the supply chain (Uchneat, 2013).

If a public garden determines that it had a unique plant with the potential for release, it needs to reach out to a plant development or marketing company to get input on the 
best path forward. This company will then coordinate the trialling process and use the results to determine whether the plant would be viable in the market.

Even before reaching out to a partner organisation, there are some dos and don'ts for the institution in the process of selecting a plant:

- Do take lots of good photographs of the plant in a garden setting. Remember, you are also marketing your plant to these companies.

- Do record cultural and phenological data so that you can provide as much information as possible to a potential partner company.

- If the plant was created through an active breeding programme, do record pedigree information as it may be needed in a patent application or to direct future crosses.

- If the plant is given to a company (licensor) for trial by your organisation (licensee), do be sure to sign a trial/testing agreement that indicates limited ownership and use by the licensor. The agreement should also state that any sports or mutations that occur during the trial must be reported immediately and are owned by the licensee.

- Do test for viruses and propagate in tissue culture. This can be expensive, but can pay off in the long run. The presence of microorganisms within plant tissue can be a major setback for a plant introduction. Ridding plants of virus or bacteria costs time and money. If the selected plant is tested, determined to be clean and then put into tissue culture, it is then protected from viral and bacterial vectors for the future.

The list of don'ts is of equal importance to the list of dos and can significantly impact the revenue potential for an introduction:

- Do not share the plant with any other organisations unless a trial agreement has been signed and states what the organisation can and cannot do with the plant.

- Do not name the plant and publicise it in any way.

- Do not sell the plant to anyone. Once a cultivar name has been publicly announced or the plant has been sold, this sale can start the clock on the window to patent. When applying for a plant patent, the United States Patents and Trademark Office will do a background check on the plant material and reject any application for a plant that has been sold, named or publicised for any time period greater than one year of the application. Simply naming a plant and putting it into a garden newsletter can start this one-year patent clock.

\section{THE CONVENTION OF BIOLOGICAL DIVERSITY AND THE NAGOYA PROTOCOL}

Any public gardens or other breeder considering a plant introduction needs to be aware of the Convention of Biological Diversity (CBD) and the Nagoya Protocol (NP). Some 
breeders and breeding companies underestimate the importance of these and may even be unaware that they exist at all. The essence of the CBD is that countries have the sovereign rights over their native genetic resources. Government permission must be granted in order to collect and export wild-collected plant material. If the wild-collected plant, its parts or derivatives from this plant are commercialised, a benefit-sharing agreement needs to be in place with the country of origin, which is outlined in the NP. Arranging a memorandum of understanding or contract for benefit sharing between countries can be lengthy and difficult. For this reason, many breeding companies and public gardens avoid using non-domestic wild-collected material in their breeding programmes.

Lack of awareness of the CBD and NP is most likely to stem from the fact that every country in the world has ratified the CBD with the exception of the USA and Vatican City (CBD, 2016). However, more breeding companies are realising the importance of the $\mathrm{CBD}$ and are working with countries to commercialise their native species and share royalties from these products to help with conservation in the country of origin (Wright, 2016). Furthermore, most USA public gardens that release plants have adopted the CBD and NP and operate within their frameworks.

\section{COMMERCIAL RELEASE}

Even if a selected plant is successful in the trial phase, there are still many stages to be completed before the plant will be available to purchase. Prior to the 1980s, even within organisations which focus on plant development, there was little marketing and few patents for new introductions. Because of this, much less thought was put into the release strategy for commercial plants (Schoellhorn, 2009). In the early 1980s, the number of patented plants on the market began to rise (Fig. 5). With the increase in patents and associated royalties came an increase in the funds invested in the process, and significant amounts of money began to be spent on trials, patents, marketing and promotion. Schoellhorn (2009) states that although there is an increasing number of patented plants on the market, there is only a certain amount of capital available to be invested in these plants and therefore the number of releases each year is more limited. This effect became apparent in the early 2000s when the number of patent applications and grants in the US levelled off somewhat (Fig. 5). Even though patent applications and grants have become flat, in recent years there have still been about 1,000 patents granted per year. This number shows that there is still plenty of room for new plants for the horticulture industry.

Plants can only be protected by a patent in the USA. In other countries throughout the world, new plant introductions are protected by plant breeders' rights (PBR). These are two equivalent systems to protect plants, and one or the other will need to be applied for depending on whether the plant is introduced in the USA (patent) or another country (PBR).

In addition to protecting the plant, propagation protocols, liner production protocols, distribution, marketing materials and plant tags will need to be developed. Most of these 


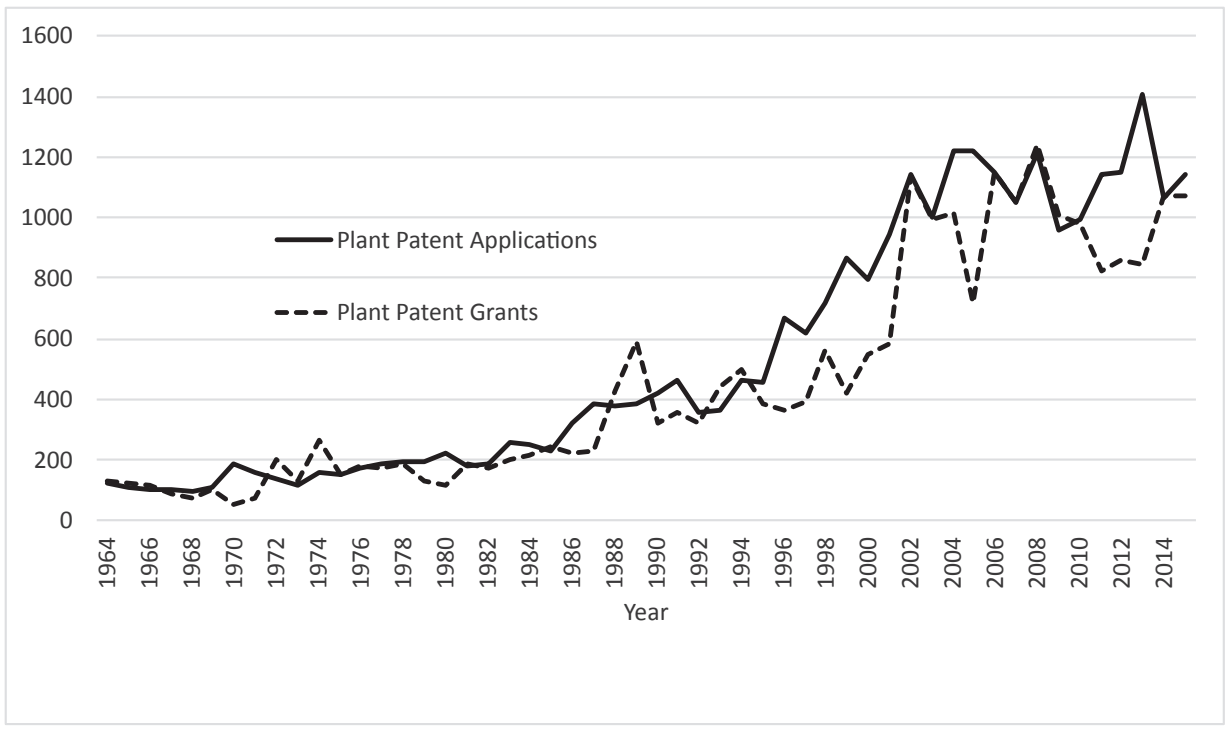

Fig. 5 Number of plant patent applications and grants in the United States 1964-2015.

items are outwith the operative toolbox of public gardens. It is important to have a strong and capable marketing partner to manage these requirements. Depending on the plant, there could be many organisations who want to be a partner for the introduction. On the other hand, there may only be one organisation willing to take a risk on a new plant. Partnership options are often dependent on the plant in question and its attributes. An effective way to evaluate a possible partnership is to talk with others who have collaborated with the company in question. Discuss the pros and cons of the partnership and any challenges that have had to be overcome. It is important to select a partner with a philosophy that matches that of the institution.

The total cost of the development process is another important aspect of a plant introduction. Schoellhorn (2012) states that introducing and marketing a plant can cost from $\$ 6,000$ to $\$ 20,000$ (Table 2). This range is broad, but on average costs are likely to come in at around $\$ 10,000$ (Schoellhorn, 2012). Other than plant development, the costs outlined in Table 2 will be incurred by the partner organisation or licensor. Some of these are likely to be repaid from funds generated by royalties. Once these debts are paid, royalty payments will begin to go to the licensee. The specific details of this should be spelled out in the contract and royalties per plant can range from a few cents for annual plants to over $\$ 1$ for some woody plants.

\section{CONCLUSION}

Commercial plant introduction by public gardens can be a valuable tool for marketing, promotion and revenue. Over the past 85 years, the United States National Arboretum 


\begin{tabular}{|l|c|c|}
\hline \multicolumn{1}{|c|}{ Process } & Time (years) & Cost (\$US) \\
\hline Breeder finds or develops new crop & $3-7$ & $1,000-?$ \\
Trial agreement signed and trials started & $1-3$ & 1,000 \\
Decision to release/patent costs & - & 3,000 \\
Tissue culture/virus cleaning & $1-2$ & 3,500 \\
Build stock & 1 & 2,000 \\
1st year marketing & 1 & 4,000 \\
Production begins & 1 & - \\
First royalty cheque & $1-2$ & - \\
2nd year marketing & 1 & 2,000 \\
3rd year marketing & 1 & $?$ \\
Competitors emerge/Product life span determined & $3-5$ & $?$ \\
\hline Total from when trials begin & $5-10$ & $6,000-20,000$ \\
\hline
\end{tabular}

Table 2 Timeframe and cost for new plant introductions. Each of these can vary greatly depending on the crop. Compiled from Schoellhorn (2012).

(USNA) has released 679 different selections (Stefan Lura, USNA, pers. comm.), a greater number than any public garden in the United States. Some of these selections carry cultivar names connected to US history. The USNA plant release programme supports the mission, brings recognition to the Arboretum, builds its reputation and has the potential to generate revenue. This is another example of a prolific programme of plant release resulting from decades of research and breeding by numerous plant breeders and scientists. The significant resources put into this programme also demonstrate that selection and development of a commercially viable plant is not as simple as one may think. The characteristics that gardeners and plant enthusiasts find interesting can be different from the characteristics of successful commercial plants. Furthermore, the majority of plants that enter the trial programmes of plant marketing companies do not make it to market.

Nevertheless, there are still opportunities and niches from plants that public gardens occupy and will continue to fill, as not all extraordinary plants are suited for the mass market. In fact, the majority of plants that have been released by public gardens have not been patented or protected, and few have been picked up by large horticultural production companies. Longwood Gardens has been associated with more than 130 plant releases since 1956 and not one carries a plant patent. Recently, Longwood recognised that by not pursuing commercial release and a patent on suitable plants, the release would not reach full potential. This realisation led to the development of guidelines for plant release with two distinct paths. The first is described in this article and involves partnering with a company specialising in plant introduction such as Ball, Blooms of Bressingham, Monrovia, PlantHaven, Plants Nouveau, Plant Select or Proven Winners. However, this path is not viable for many of the niche plants which have been and will continue to be developed at Longwood. 
The second is the release of plants through non-commercial methods. These are freely distributed to other public gardens and carry the Longwood name. Examples of this are Camellia japonica 'Longwood Centennial', Caryopteris $\times$ clandonensis 'Longwood Blue' and Mandevilla 'Alice du Pont'. This method is much simpler and the strategies for release, marketing and distribution are driven solely by Longwood. The potential for revenue is minimal, but nevertheless these plants continue to serve as a promotion tool for marketing and support Longwood's mission of excellence in horticulture.

\section{REFERENCES}

ANIŚKO, T. (2006). Plant Exploration for Longwood Gardens. Timber Press, Portland, OR.

CBD (2016). List of Parties. Available at www.cbd.int/information/parties.shtml (accessed July 2016).

BRICKELL C., ALEXANDER, C., DAVID, J., HETTERSCHEID, W., LESLIE, A., MALECOT, V. \& JIN, X. (2009). International Code of Nomenclature for Cultivated Plants. Scripta Horticulturae, 10, 8th edn, International Society of Horticultural Science, Leuven.

D'ALESSIO, N., BOYLE, K., BOSCH, D., HARTTER, D. \& PEASE, J. (2015). Adding value to ornamental plants. American Nurseryman, December, 16-18.

LIGHTY, R.W. (2000). An assessment of ornamental plant introduction in the not-for-profit sector. In: AULT, J.R. (ed.), Plant Exploration: Protocols for the Present, Concerns for the Future. Symposium Proceedings, 18-19 March 1999, Chicago Botanic Garden, Glencoe IL, pp. 14-22.

SCHOELLHORN, R. (2009). Strategies for Plant Introduction and Market Trends in the US. Acta Horticulturae, 813, 101-106.

SCHOELLHORN, R. (2012). Proven winners. Trials and Tribulations, Points You Really Need to Know to Get Your Hybrids to Market. Handout from 2012 Independent Plant Breeders Conference, 1-4 November, Portland, OR.

UCHNEAT, M. (2013). The Importance of Plant Trials to the Breeder. Proceedings of the 2013 International Trials Conference, 16-20 September, Longwood Gardens, Kennett Square, PA.

UNITED STATES DEPARTMENT OF AGRICULTURE (USDA) (2014). Census of Horticultural Specialties. Issued December 2015. AC-12-SS-3.

UNITED STATES PATENTS AND TRADEMARK OFFICE (1994). Available at www.uspto. gov (accessed July 2016).

WRIGHT, J. (2016). Breeders go the distance to bring new varieties to market. Greenhouse Grower, April, 50-52. 